\title{
Online Dating: Is Hooking Up the Goal?
}

\author{
Lindsey Almond ${ }^{1 *}$, Kate Taylor Harcourt-Medina ${ }^{2}$, and Alan Taylor ${ }^{2}$ \\ ${ }^{1}$ Department of Human Development and Family Studies, Auburn University, Auburn, AL, United States \\ ${ }^{2}$ Department of Human Development and Family Science, East Carolina University, Greenville, NC, United States \\ Email: 1la0009@auburn.edu
}

\begin{abstract}
This study examines how gender interplays with emerging adults' intentions and outcomes when using online dating. Symbolic interaction and evolutionary theories are used to understand how evolutionary symbols are associated with online dating, impacting intentions and outcomes. Utilizing a sample of 229 emerging adults, between 18-30 years of age, regression analyses show online dating intentions and outcomes associated with online dating (e.g., whether it was a casual or sexual relationship or if their desired partner demographics were matched), are predicted by gender. Men were found to both seek casual, sexual relationships and have casual, sexual relationships when using online dating more than women. Though online dating has promoted a new path towards dating through technology, these results suggest online dating is similar to traditional dating. Further research is needed to examine the effects of gender on relationship quality, longevity, and theories of online dating relationships.
\end{abstract}

Keywords: Dating, online, romantic relationships, gender

\section{Introduction}

Emerging adults are often engaging in prolonged phases of dating. Although many eventually marry, the age at which adults choose to marry has been delayed to late 20s or early 30s (Willoughby, Hall, \& Luczack, 2015), and cohabitation rates are increasing (Willoughby et al., 2015). Even with these trends, many are still interested in establishing serious romantic relationships (Taylor, Rappleyea, Fang, \& Cannon, 2013), which often include both physical and emotional intimacy (Sumter, Vandenbosch, \& Ligtenberg, 2017).

Within the U.S., many emerging adults choose to attend college, where this prolonged trend of dating is common (Brimeyer \& Smith, 2012). Research shows emerging adults desire an array of romantic experiences (Rappleyea, Taylor, \& Fang, 2014). Both serious and casual romantic relationships allow emerging adults to explore their sexuality, intimacy, and desires (Hall, Lee, \& Witherspoon, 2014). However, instead of establishing longer, more serious romantic relationships, emerging adults are often engaging in more casual relationships such as hooking up, friends with benefits, and dating without commitment (Hall et al., 2014). The experiences that come with their exploration in romantic relationships may influence their later romantic decisions (Halpern-Meekin, Manning, Giordano, \& Longmore, 2013).

\subsection{Online Dating}

As college students and emerging adults search for potential romantic partners, they desire to expand their pool of eligible partners. Many emerging adults have access to smartphones which allow them easier access to online dating sites and apps. Though online dating has gained momentum recently (Sautter, Tippett, \& Morgan, 2010), it is still developing and evolving. Online dating allows individuals to engage in casual romantic searching, without commitment (Barraket \& Henry-Waring, 2008; Taylor et al., 2013). Online dating has become popular due to the ease and accessibility to meet new people, as well as for its increased social acceptance (Sautter et al., 2010).

In 2016, approximately 38\% of singles had tried online dating (Gatter \& Hodkinson, 2016). The intentions to use these sites varies. Research has shown that the main reasons for emerging adults to engage in online dating is to find friendships, engage in dating relationships, engage in sexual relationships, meet new people, find love, and for self-worth validation (Sumter et al., 2017). The 
reasons people use online dating and the perceptions they have about online dating are formed through social and cultural symbols, such as online dating being unsafe or using technology as being time efficient (Barraket \& Henry-Waring, 2008). These socio-cultural symbols of online dating are constantly changing over time. Overall though, the negative stigma associated with online dating has seemed to decrease, and instead, the use of such sites has increased as a reputable source to find a serious romantic partner (Ellison, Heino, \& Gibbs, 2006). Though, face-to-face encounters were previously the most common way of meeting a potential romantic partner, these forms of contact have been decreasing over the past 10 years (Gatter \& Hodkinson, 2016).

\subsection{Gender}

Men and women have been shown to differ in certain aspects of online dating. In general, men are more likely to be comfortable using online dating (Rappleyea et al., 2014). In traditional dating, men have been found to be more interested in casual, sexual relationships, whereas women are more interested in friendships (Gatter \& Hodkinson, 2016; Taylor et al., 2013). Men and women both acknowledge that technology has the ability to further a dating relationship (Taylor et al., 2013); however, men generally have more relational power in-person rather than through technology. It is possible that online dating provides women more relational power as their pool of potential romantic partners is expanded.

For emerging adults on college campuses, women outnumber men (Brimeyer \& Smith, 2012). With men in short supply, they hold more power to control what the relationship looks like (Hall et al., 2014). According to Brimeyer and Smith (2012), men also hold power because they place less value and interest in the relationship than women do. This results in women lowering their expectations for a potential romantic partner (Hall et al., 2014). With the growing emergence of online dating opportunities, women may use online dating to exert more control over their potential relationships than in-person dating. The inclusion of online dating sites in studies examining control is needed to see what, if any, gender differences exist.

\subsection{Theoretical Framework}

This study utilizes Symbolic Interactionism theoretical framework and Evolutionary theory. Symbolic Interactionism states that experiences and interactions create symbols that continuously evolve (Blumer, 1969). When assessing romantic relationships, as individuals age and gain dating experience, their symbolic views of relationships tend to change (Willoughby et al., 2015). With prolonged dating, symbols of romantic feelings, intentions, and perceptions revolve around their experiences, including online dating. As the societal view on marriage, online dating, and romantic relationships evolve, research must focus on how an individual's beliefs and attitudes influence their actions (Willoughby et al., 2015). Therefore, cultural society may play a role in determining the symbolic associations individuals have towards online dating.

Cultural society has also influenced the evolutionary expectations of romantic couples. Within the context of dating, evolutionary theory claims individuals will attempt to engage in behaviors to attract others and further themselves (Abramova, Baumann, Krasnova, \& Buxmann, 2016). Those within a dating phase, are in competition with their peers to attract the best romantic partner that can provide for their, and any offspring's, evolutionary and materialistic needs (Abramova et al., 2016). Specifically, women exhibit higher levels of selectivity when looking for a romantic partner because women within the United States are culturally expected to spend more time and effort throughout child rearing than their male counterparts (Abramova et al., 2016; Barraket \& Henry-Waring, 2008). Men on the other hand, are predisposed to seeking more short-term pleasure and with less selectivity (Abramova et al., 2016). Abramova et al. (2016) has found tremendous support for gender differences in reference to evolutionary theory within dating but calls for extended research to explore the theory in the context of online dating.

\subsection{Present Study}

This study seeks to understand if gender predicts differences in the intentions individuals have when engaging in online dating and the results that occur from their online dating usage. Authors hypothesize 
that both men and women utilize online dating in similar ways to more traditional forms of dating initiation. Symbolic interaction and evolutionary theories are used to better understand how the symbols people associate with online dating impact their intentions. Specifically, why one gender may have a disposition towards certain intentions and results when using online dating. The way in which these symbols, from an evolutionary perspective, are interpreted may impact someone's desire to pursue a romantic relationship. This study helps to achieve a better view of how gender influences online dating through the research questions:

Research question 1: Do online dating intentions differ by gender?

Research question 2: Does online dating usage differ by gender?

\section{Methods}

\subsection{Sample}

Initially, 628 individuals started the online dating survey; however, our final sample for this study, which included fully completed surveys and individuals who reported having used online dating only, was 229 emerging adults. Participants were between 18-30 years of age with 130 females (56.8\%) and 99 males $(43.2 \%)$. Participants were removed from the study if they indicated that they had not used online dating; they were also removed if they did not fall within the targeted age range or identified as a gender other than male or female due to low response numbers. This paper utilizes gender instead of sex as the determinate due to participants being asked to report their gender as either male, female, or other. Since the questionnaire asked about gender, rather than biological sex, participants could report whichever gender they identified as.

Table 1. Demographic characteristics

\begin{tabular}{llll}
\hline \multicolumn{1}{c}{ Variable } & Men $(\boldsymbol{M}(\boldsymbol{S D})$ or $\%)$ & Women $(\boldsymbol{M}(\boldsymbol{S D})$ or $\%)$ & Total \\
\hline Gender & $43.20 \%$ & $56.80 \%$ & $100 \%$ \\
\hline Age & $21.29(2.484)$ & $21.05(2.695)$ & \\
\hline Race & & & $53.16(2.603)$ \\
Caucasian & $50.50 \%$ & $56.20 \%$ & $29.30 \%$ \\
African American & $37.40 \%$ & $23.10 \%$ & $6.10 \%$ \\
Hispanic & $2.00 \%$ & $9.20 \%$ & $6.10 \%$ \\
Asian & $5.10 \%$ & $6.90 \%$ & $0.90 \%$ \\
Native American & $0.00 \%$ & $0.80 \%$ & $0.40 \%$ \\
Pacific Islander & $0.00 \%$ & $1.50 \%$ & $3.50 \%$ \\
Other & $5.00 \%$ & $2.30 \%$ & \\
Sexual Orientation & & & $86.50 \%$ \\
Heterosexual & $86.70 \%$ & $86.90 \%$ & $4.40 \%$ \\
Homosexual & $8.20 \%$ & $1.50 \%$ & $7.00 \%$ \\
Bisexual & $2.00 \%$ & $10.80 \%$ & $2.10 \%$ \\
Other & $3.10 \%$ & $0.80 \%$ & \\
Relationship Status & & & $45.90 \%$ \\
Single & $47.50 \%$ & $44.60 \%$ & $32.30 \%$ \\
Dating an Exclusive Partner & $30.30 \%$ & $16.30 \%$ & $16.60 \%$ \\
Talking to Someone & $17.20 \%$ & $33.80 \%$ & $3.50 \%$ \\
Engaged & $3.00 \%$ & $3.80 \%$ & $1.30 \%$ \\
Married & $1.00 \%$ & $1.50 \%$ & $0.40 \%$ \\
Widowed & $1.00 \%$ & $0.00 \%$ &
\end{tabular}

Students and non-students in a mid-Atlantic region were invited to complete an online survey regarding their technology use. Participants were recruited through multiple college classrooms and Facebook. Individuals who completed the survey were invited to share the survey link with other students and non-students who fit the criteria. The ethnicity of the sample comprised of (53.7\%) 
Caucasian, (29.3\%) African American, (6.1\%) Hispanic, (6.1\%) Asian, (0.9\%) Native American, (0.4\%) Pacific Islander, and (3.5\%) other. A majority of the sample identified themselves as heterosexual $(86.5 \%)$, while $4.4 \%$ identified as homosexual, $7.0 \%$ as bisexual, and $2.1 \%$ as other. The relationship status of the sample was $(45.8 \%)$ currently single, (30.5\%) currently dating an exclusive partner, (14.8\%) currently "talking to someone", (3.4\%) engaged, (1.3\%) married, (0.4\%) widowed, and (3.8\%) no response.

\subsection{Measures}

Authors were interested to understand if intentions and results of online dating correlated. Therefore, we asked participants who had tried online dating to report all of the intentions they had when using online dating (e.g. find friendships, find casual/sexual relationships, find casual/dating relationships, find committed/dating relationships, self-worth validation), and all of the outcomes from their online dating involvement (e.g. friendship, casual/sexual relationship, casual/dating relationship, committed/dating relationship, self-worth validation).

\subsection{Analysis}

Regressions were conducted to determine if gender predicted the intentions and results of online dating using SPSS version 23 (IBM, 2015). Simple linear regressions were chosen to look at the relationship between two variables (Afifi, May, \& Clark, 2014); gender was a constant predictor variable, while the intentions and results of online dating served as various outcome variables. Due to having more than 30 observations in each group, the authors follow the Central Limit Theorem and assume normal distribution (Dinov, Christou, \& Sanchez, 2008).

\section{Results}

\subsection{Intentions of Online Dating}

Simple linear regressions were conducted to determine if gender predicted individual intentions when using online dating. Results of the simple linear regressions indicated there was a significant effect between gender and the intention of casual, sexual relationships $\left(F(1,228)=49.30, p<.000, R^{2}\right.$ $=.178)$. Males were more likely to report an intention of casual, sexual relationships from their online dating usage $(\beta=.422, p=.000$; see Table 2$)$. There were no statistically significant findings between gender and other intentions.

Table 2. Intentions of online dating

\begin{tabular}{llllll}
\hline Intention & $B$ & $S E B$ & $\beta$ & $t$ & $p$ \\
\hline Friendships & -0.024 & 0.067 & -0.024 & -0.36 & 0.72 \\
Casual Sexual Relationships & -0.423 & 0.060 & -0.422 & -7.02 & 0.00 \\
Casual Dating Relationships & 0.029 & 0.660 & 0.029 & 0.439 & 0.66 \\
Committed Relationship & 0.071 & 0.061 & 0.077 & 1.161 & 0.25 \\
Self-Worth Validation & 0.064 & 0.055 & 0.077 & 1.166 & 0.25 \\
\hline
\end{tabular}

\subsection{Results of Online Dating}

Simple linear regressions were conducted to determine if gender predicted individual results when using online dating. Results of the simple linear regressions indicated there was a significant effect between gender and the outcome of casual, sexual relationships $\left(F(1,228)=4.55, p=.034, R^{2}=.020\right)$. Males were more likely to report a result of casual, sexual relationships from their online dating usage $(\beta$ $=.140, p=.034$; see Table 3$)$. There were no statistically significant findings between gender and other outcomes. 
Table 3. Outcomes of online dating

\begin{tabular}{llllll}
\hline & $B$ & $S E B$ & $\beta$ & $t$ & $p$ \\
\hline Friendships & 0.084 & 0.067 & 0.083 & 1.257 & 0.21 \\
Casual Sexual Relationships & -0.14 & 0.066 & -0.14 & -2.13 & 0.03 \\
Casual Dating Relationships & 0.015 & 0.063 & 0.016 & 0.241 & 0.81 \\
Committed Relationship & 0.006 & 0.057 & 0.007 & 0.108 & 0.91 \\
Self-Worth Validation & -0.03 & 0.052 & -0.04 & -0.63 & 0.53 \\
\hline
\end{tabular}

\section{Discussion}

Researchers were interested in understanding if gender predicted the intentions and results of online dating. Specifically, the research questions were: do online dating intentions differ by gender, and does online dating usage differ by gender?

When engaging in online dating, gender did influence the intention of casual, sexual relationships. Specifically, men were found to use online dating with the intentions of finding casual, sexual relationships more than women. This is supported by previous research finding that men are generally more likely to look for this type of relationships than women (Gatter \& Hodkinson, 2016). As men have a greater power in relationships on a college campus where women are the majority, men may be less likely to settle into one committed relationship (Hall et al., 2014). No statistically significant differences were found between males and females on their intentions to find friendships, casual dating relationships, committed relationships, or self-worth validation. This may be due to the increased use and social acceptance of online dating (Hobbs, Owen, \& Gerber, 2017). Emerging adults are more likely than any other age group to move, creating higher likelihood of loneliness (e.g., Berk \& Myers, 2016), which could result in both men and women using online dating as a way to meet people with both romantic and non-romantic intentions.

Significant gender differences were also found regarding whether individuals have engaged in casual, sexual relationships. Our results suggest men are more inclined to both look for casual, sexual relationships through online dating and have results of casual, sexual relationships from their online dating experiences. Through the theoretical lens of symbolic interactionism and evolutionary theory, experiences and interactions with online dating continue to adapt within society (Blumer, 1969). The individual intentions and results of romantic relationships through online dating are influenced by the societal views and opinions (Willoughby et al., 2015). Men have historically held the power and resources when it comes to romantic relationships (Hall et al., 2014). Conversely, women have experienced historical selectiveness when choosing a partner due to the costs associated with childbearing and lack of resources (Hall et al., 2014). These gender norms, supported by our results, follow the evolutionary theory associated with the pleasure seeking of men and the commitment seeking of women within romantic relationships (Abramova et al., 2016).

\subsection{Limitations}

This study focuses on emerging adults; however, a large majority of the sample were college students. College students have been reported to engage in prolonged dating and increased rates of hooking up or sexual exploration, which may influence the symbols they associate with online dating (Brimeyer \& Smith, 2012; Hall et al., 2014). Emerging adulthood is a crucial period for the development of relationship skills such as navigating the ebb and flow of romantic and sexual relationships (HalpernMeekin et al., 2013). For emerging adults who decide an alternative path than college, such as vocational training, the workforce, or the armed forces, relationship skills may be experienced in a different way. While the college environment provides access to meeting numerous people (Hall et al., 2014), alternative paths may not provide as many opportunities to engage with a variety of potential romantic partners. Therefore, emerging adults who do not attend college may choose to use online dating services as a resource to meet more people.

With over half of the participants reporting their ethnicity as Caucasian, this study was not evenly dispersed amongst a variety of ethnicities. Halpern-Meekin et al. (2013) states the personal and social 
characteristics of an individual influence their views and behaviors associated with romantic relationships. For many Caucasian individuals, college is a likely path after completing high school with the U.S. Bureau of Labor (2016) reporting approximately $70 \%$ immediately attend a college or university compared to $58 \%$ of African Americans. As college is generally a path for those with wealth or resources, individuals who attend may have differing backgrounds and ways of thinking than those who do not attend college.

This study inquired about the participant's gender, but not sex. The questionnaire did provide an option for participants to choose male, female, or other for their gender, but did not provide an outlet to expand on what 'other' may mean to the participant. With only two participants reporting 'other,' researchers were not able to explore the beliefs of transgendered individuals on online dating. Likewise, due to participants reporting low numbers of same-sex relationships only heterosexual couples were studied. Sumter et al. (2017) has previously supported the idea that online dating usage is motivated differently depending on a person's characteristics such as gender. The struggle to be accepted as a transgendered individual can lead emerging adults to develop a sense of loneliness and may disengage from normative college environments (Duran \& Nicolazzo, 2017). Even though transgendered individuals are less likely to 'be out' to anyone other than their close friends and family, potential romantic partners report feeling as if the transgendered individual is being deceptive if they do not automatically reveal their gender identity (Duran \& Nicolazzo, 2017). This may discourage the pursuit of a romantic relationship in general as transgendered individuals feel their gender identity is what potential partners view them as, rather than encompassing their personality and other characteristics (Duran \& Nicolazzo, 2017). A further study of online dating looking at transgender individuals, or same-sex couples would add to the literature on diverse types of people and relationships.

\section{Conclusion and Implications}

This study aids in better understanding the differences in the way self-identified males and females perceive and utilize online dating services. As trends continue to shift, there are lower rates of men are asking women out in a traditional, face to face way (Brimeyer \& Smith, 2012; Hall et al., 2014). Brimeyer and Smith (2012) report the longer an individual stays in college, the more likely they are to have a casual "hook up." For those in a relationship, individuals may feel more secure with the idea of breaking up with their partner because online dating provides numerous alternative options (Hobbs et al., 2017). In fact, Halpern-Meekin et al. (2013) find that emerging adults may experience many break ups and reunification with the same partner. These individuals may use online dating during their separation as an effortless way to find a hook up or engage in leisurely connections (Hobbs et al., 2017). Results from this study support these previous findings on emerging adult's romantic relationships and demonstrate similarities between traditionally initiated dating and online dating. Increased research could seek to understand the patterns of online dating usage and how it integrates into an on and off relationship between two individuals. This may provide therapists with on and off again couples, further insight into the acceptability of online dating in this form of relationship.

Symbols such as sexual or emotional infidelity are often associated with cheating in a committed romantic relationship. The anonymity that is sometimes associated with online dating introduces new methods of cheating. Emerging adults in committed romantic relationships must navigate what sort of technological use is considered cheating within their relationship. While our sample use online dating services, there were different percentages of each intention; $44.1 \%$ desired to find a sexual relationship, $43.7 \%$ wanted friendships and, $57.2 \%$ looked for casual dating relationships, $29.3 \%$ hoped to find committed relationships, and $21.8 \%$ merely used online dating to foster their sense of self-worth. With similar rates of friendship, sexual, and dating relationship motivations, individuals must consider their partner's intentions when using an online dating service while in a committed relationship to determine their acceptance of use. Further research should seek to better understand if individuals in an on and off romantic relationship use online dating services, and if so what their intentions are. Research should also address the transparency of this use between the on and off again partners. This research could examine if women or men are more likely to use these services while in this type of relationship. Our results suggest men use online dating with the intentions of sexual relationships more than women. If the same 
is true for men in on and off relationships, it is likely they will be less transparent about their online dating usage.

The new findings from this study pose online dating as similar in intentions and outcomes when compared to traditionally initiated dating. This is important for individuals working with emerging adults about romantic relationships. Specifically, in relationship education programs, online dating is a normative dating process that needs to be incorporated. This study and previous research suggest that intention within online dating relationships is also important to include when discussing healthy relationship practices. Though both genders find intimate and sexual relationships important during emerging adulthood, a shift from committed to casual relationships is occurring among emerging adults (Hall et al., 2014). Further research is still needed to understand the symbols evolving from online dating. With rapid technological advances, researchers should strive to stay updated on the current practices and how they influence society.

\section{References}

1. Abramova, O., Baumann, A., Krasnova, H., \& Buxmann, P. (2016). Gender differences in online dating: What do we know so far? A systematic literature review. Paper presented at the Annual Hawaii International Conference on System Sciences, 2016, 3858-3867. doi:10.1109/HICSS.2016.481

2. Afifi, A., May, S., \& Clark, V. A. (2014). Practical multivariate analysis, fifth edition. J. Bergman (Ed.). Boca Raton, Florida: Chapman \& Hall/CRC.

3. Barraket, J., \& Henry-Waring, M. S. (2008). Getting it on(line): Sociological perspectives on e-dating. Journal of Sociology, 44(2), 149-165. doi:10.1177/1440783308089167

4. Berk, L \& Myers, A. (2016). Infants, children, adolescents $8^{\text {th }}$ edition. Boston, MA: Allyn \& Bacon.

5. Blumer, H. (1969) Symbolic Interactionism; Perspective and Method. Englewood Cliffs, NJ: Prentice-Hall

6. Brimeyer, T. M., \& Smith, W. L. (2012). Religion, race, social class, and gender differences in dating and hooking up among college students. Sociological Spectrum, 32(5), 462-473. doi:10.1080/02732173.2012.694799

7. Dinov, I. D., Christou, N., \& Sanchez, J. (2008). Central limit theorem: New SOCR applet and demonstration activity. Journal of Statistics Education, 16(2). doi:10.1080/10691898.2008.11889560

8. Duran, A., \& Nicolazzo, Z. (2017). Exploring the ways trans collegians navigate academic, romantic, and social relationships. Journal of College Student Development, 58(4), 526-544. doi:10.1353/csd.2017.0041

9. Ellison, N., Heino, R., \& Gibbs, J. (2006). Managing impressions online: Self-presentation processes in the online dating environment. Journal of Computer-Mediated Communication, 11(2), 415-441. doi:10.1111/j.10836101.2006.00020.x

10. Gatter, K., \& Hodkinson, K. (2016). On the differences between tinder versus online dating agencies: Questioning a myth. An exploratory study. Cogent Psychology, 3(1) doi:10.1080/23311908.2016.1162414

11. Hall, N. M., Lee, A. K., \& Witherspoon, D. D. (2014). Factors influencing dating experiences among African American emerging adults. Emerging Adulthood, 2(3), 184-194. 10.1177/2167696813520154

12. Halpern-Meekin, S., Manning, W. D., Giordano, P. C., \& Longmore, M. A. (2013). Relationship churning in emerging adulthood: On/Off relationships and sex with an ex. Journal of Adolescent Research, 28(2), 166-188. doi:10.1177/0743558412464524

13. Hobbs, M., Owen, S., \& Gerber, L. (2017). Liquid love? dating apps, sex, relationships and the digital transformation of intimacy. Journal of Sociology, 53(2), 271-284. doi:10.1177/1440783316662718

14. IBM Corp. (2015). IDM SPSS Statistics for Macintosh, Version 23.0. Armonk, NY: IBM Corp.

15. Rappleyea, D. L., Taylor, A. C., \& Fang, X. (2014). Gender differences and communication technology use among emerging adults in the initiation of dating relationships. Marriage \& Family Review, 50(3), 269-284. doi:10.1080/01494929.2013.879552

16. Sautter, J., Tippett, R., \& Morgan, S. (2010). The social demography of internet dating in the United States. Social Science Quarterly, 91(2), 554-575.

17. Sumter, S. R., Vandenbosch, L., \& Ligtenberg, L. (2017). Love me tinder: Untangling emerging adults' motivations for using the dating application tinder. Telematics and Informatics, 34(1), 67-78. doi:10.1016/j.tele.2016.04.009

18. Taylor, A. C., Rappleyea, D. L., Fang, X., \& Cannon, D. (2013). Emerging adults' perceptions of acceptable behaviors prior to forming a committed, dating relationship. Journal of Adult Development, 20(4), 173-184. doi:10.1007/s10804-013-9169-3 
19. U.S. Bureau of Labor Statistics. (2016). The economics daily [Data file]. Retrieved from https://www.bls.gov/opub/ted/2017/69-point-7-percent-of-2016-high-school-graduates-enrolled-in-college-inoctober-2016.htm

20. Willoughby, B. J., Hall, S. S., \& Luczak, H. P. (2015). Marital paradigms: A conceptual framework for marital attitudes, values, and beliefs. Journal of Family Issues, 36(2), 188-211. doi:10.1177/0192513X13487677 